\title{
Modelling Domestic Tourism Demand for Ghana
}

\author{
Ebenezer Kojo Ocran ${ }^{1}$, Professor O. A. Adebanji ${ }^{2}$, Dr. Solomon Sarpong ${ }^{3}$ \\ 1. Ghana Statistical Service, Accra, Ghana \\ 2. Kwame Nkrumah University of Science and Technology, Kumasi, Ghana. \\ 3. University for Development Studies, Tamale, Navrongo Campus, Navrongo, Accra, Ghana
} Abstract

The research analyses the demand for tourism goods and services in Ghana by domestic tourists. For this purpose, it uses the Linear Almost Ideal Demand System (LAIDS) model (static and dynamic) to estimate price and expenditure/income elasticities for the study. The tourism goods and services include: accommodation; food and drinks; transport; recreation, culture and sporting activities; shopping; and other services. The uncompensated and compensated price and expenditure/income elasticities were calculated from the estimated parameters of the LAIDS model, static and dynamic. The results show that all own-price elasticities are negative and significant for uncompensated and compensated elasticities, while expenditure/income elasticities are positive and significant. The findings show that, by short-run, the demand for tourism goods and services in Ghana is price inelastic and expenditure/income elastic, and are normal goods and services.

KEY WORDS: Static, dynamic, uncompensated, compensated, AIDS, elasticity.

DOI: $10.7176 /$ JTHS/40-09

\section{Introduction}

For the past few years, tourism has become the world's largest and fastest growing sector, and serves as a major earner of foreign exchange (UNWTO, 2015). Owing to this, copious attempts have been made to comprehend the main components of tourism demand, with the sole aim to formulate, discuss, develop, implement and evaluate appropriate policies and strategies to attract more visitors (Sarath Divisekera, 2007). Tourism as a source of national revenue was recognised in Ghana as far back in 1970 when the tourist resource potentials of the country was identified by the government. Tourism Development Plan was originated in 1975 when the government of the time brought into being the first Tourism Development Plan, 1975 - 1990. Domestic tourism is a fast growing economic activity in Ghana, and in many countries around the world, which plays a significant role in the economy of nations. It helps to motivate the development of Ghana's basic infrastructure, contributes to the growth of domestic tourism industries, attracts foreign investment, and facilitates the transfer of information. One of the main reasons which encourage governments to continue to support and promote tourism is that it has a positive impact upon economic growth and development.

The main goal of domestic tourism development in Ghana is to ensure that tourism in Ghana achieves its full potential in a sustainable and responsible manner and that it would contribute to Ghana's Gross Domestic Product (GDP) to reduce poverty, to ensure that its operation will not destroy the environment as well as culture and traditions of the country and more importantly, to attract a wide range of domestic markets. Tourism is one of the main foreign exchange earnings in Ghana, including merchandise exports, remittances from abroad and oil, which was found in large quantities in 2007 and continues to show its potential as the main driver of growth (Bank of Ghana, 2007). However, its contribution to growth and job creation varies greatly across the country, due to the distribution of tourism infrastructure. Yet, it is one of the main sources of income for the population both in rural and urban communities. Ghana's domestic tourism sector, in terms of the major attractions, has huge potentials of poverty reduction and wealth creation for the people of Ghana, especially for those in the rural areas, where historical and community-based eco-tourism sites and tourism related businesses are located. However, Ghana's participation in domestic tourism activities has not been yielding the required results for the past decade (Ghana Statistical Service, 2018). According to the report, visits to the country's attractions had slowed down for the past ten years, making the demand for domestic tourism low. The main aim of the study is to estimate domestic tourism demand in Ghana using domestic tourism expenditure data from 2012 to 2017 and Linear Almost Ideal Demand System (LAIDS) models, static and dynamic. Tourism goods and services 
demanded by Ghana's domestic visitors include accommodation (ACC); food and drinks (FAD); transport (TRA); recreation, culture and sporting activities (RCS); shopping/non-consumables (SHO); and others (OTH).

\section{Measuring Domestic Tourism Demand in Ghana}

The term 'tourism demand 'is usually used to mean actual or observed tourism participation and activity. This type of demand is known as real or actual demand and refers to the aggregate number of tourists/visitors recorded in a given location or at a particular point in time (Page and Connell, 2006). Demand is the quantity of a good or service which visitors/tourists are willing and able to purchase under a given set of conditions for a given time period (Song et al, 2000). In this context, domestic tourism demand is the measurement of the volume, scale, impact and value of domestic tourism at different geographical scales from national and regional levels (Page and Connell, 2006). According to Fletchling (2001), tourism demand is the measurement of visitors' use of a good or service.

Domestic tourism demand in Ghana lags behind other countries such as United Kingdom (U. K), Germany, Australia, New Zealand, South Africa, Kenya and other African countries, in spite of the numerous attractions, visiting friends and relatives, business and professional meetings, education and training, religious camp meetings, shopping, etc., away from the concepts of 'usual residence' and 'usual environment'. In these countries, their domestic tourism consumption expenditures are greater than their international inbound tourism receipts or expenditures. In Ghana, the reverse is true, international inbound tourism (receipts) expenditures are higher than domestic tourism expenditures, and according to Ghana Statistical Service, 2018, visits to the country's attractions had slowed down for the past ten years, making the demand for domestic tourism low. There is therefore the need to investigate the determinants of domestic tourism demand in Ghana to answer for the low patronage for domestic tourism consumption.

Economic factors such as income and relative prices largely account for the demand for tourism products in Ghana. According to Song and Li (2008), it concerns decision makers in tourist destinations greatly to identify the determinants of tourism demand and estimate sizes of their effects on domestic tourism demand. To improve domestic tourism participation in Ghana, governments, policy makers and tourism practitioners are to identify the determinants of domestic tourism demand, estimate sizes of their effects on domestic tourism demand to inform policies. Due to the fact that the preferences of Ghana's domestic tourists might change overtime, the long-run behaviour is examined in the static LAIDS model, while the short-run market adjustments are assessed using the dynamic LAIDS model.

\section{Objective of the Study}

The objective of the study is to investigate the determinants of domestic tourism demand for Ghana.

\section{Literature Review}

In this section, empirical studies on AIDS models are reviewed, since most of the studies use this model for the estimation of own-price elasticities, cross-price elasticities, and income/expenditure elasticities. Economic impact of tourism goods and services' consumption by tourists or visitors has not been given much research attention, especially in Africa in general, and Ghana in particular. The Almost Ideal Demand System (AIDS) model was developed by Deaton, A. and Muellbauer, J. (1980). Since the development of this model, many researchers have been continuously using it for consumer demand analyses due to its flexible nature. Fujii et al (1985) used the AIDS model for visitor expenditures. Green and Alston (1990) also used the AIDS model for modelling tourism demand. Even though there are alternative systems modelling approaches, the Almost Ideal Demand System (AIDS) model of Deaton and Muellbauer (1980a) is considered, since it is one of the most useful frameworks to examine consumer behaviour due to its flexible nature and other longing properties. The AIDS model has been applied to model household expenditures (Blundell et al., 1994), consumption of goods (Johnson et al., 1992), and trade shares (Parikh, 1988). Several studies have also used the AIDS model to analyse tourism demand.

Tourism research has increased rapidly since the 2000. Li et al (2005) argue that there had been developments in the analysis of tourism demand in terms of multiplicity of research interest, research methodology advances and in-depth of theoretical foundations. For example, from 1990 to 2008, most of the tourism research used static econometric approaches like Generalised Least Squares (GLS), Ordinary Least Squares (OLS), and others. Athanasopoulos, G. and Hyndman, R. J. (2008) modelled Australian demand from 1998 - 2005, using OLS and 
Seemingly Unrelated Regressions while Coenen and Eekeren (2003) investigated domestic tourism demand of Swedish households' from1990 - 1996 using system equations (Quadratic AIDS).

Currently, tourism researchers have introduced more sophistication into time-series economic models, for example, dynamic or error correction model into the literature to model domestic tourism demand (Song et al, 2010). Despite the fact that econometric time-series regressions has been in the literature for some time, analysis of panel data has been uncovered in the domestic tourism demand research literature (Divisekera (2007).

For example, Divisekera (2007), uses AIDS model to estimate demand elasticities for Australian tourists. The system of demand equations used which expressed demands as a function of relative prices and real expenditure was non-linear. Two systems of demand equations were estimated: combined or aggregate of demand of domestic tourism (national); and demands differentiated by region of destination (states/territories). The study shows that tourists' demand for different tourism products purchased by domestic tourists are less responsive to prices but more income elastic. Here, only long-run elasticity estimates are calculated, leaving out the short-run elasticities. New South Wales was the key tourist destination.

Static AIDS specifications focus on the selection of nonlinear and linear models as well as a variety of estimation methods. Some research activities which are considered to be pioneers that model U.S. tourism demand for tourism in European countries include White (1982) and Harrison (1984) who analyze the development of the shares of market of U. S. tourism spend in Europe from the year 1960-1981.

Coenen et al (2010) discuss the econometric analysis of domestic tourism demand of households in Sweden. The category of expenditure estimated include accommodation, groceries, restaurants, shopping and transportation. The AIDS model calculates price and expenditure elasticities with regards to different characteristics of households.

Sadeghi et al (2007) estimates price and expenditure elasticities for Hamedan Province in Iran using AIDS model. The results show that expenditure elasticities for the commodity groups are income/expenditure elastic but demand for commodity groups is price inelastic.

$\mathrm{Wu}, \mathrm{Li}$ and Song (2011) made an observation on the studies of Divisekera (2007) and Fujii et al (1985) that these studies use the demand systems which are regarded as a group of tourism goods and services in one destination. However, these authors, in their empirical studies, utilized the static AIDS model alone and gave estimates of long-run demand elasticities alone without taking into consideration the dynamic model to generate short-run elasticity estimates. However, this study takes into accounts the calculation of both long-run and short run elasticity estimates to determine Ghana's domestic tourists' behaviour.

Divisekera (2007), found out that the responsiveness of demand for domestic travel varies within a destination (Australia) and the main factors of domestic tourism are income of tourists, prices of tourism goods and services, prices of alternative goods and services and tourist's preference or taste. The results show that expenditure elasticities for the commodity groups are income/expenditure elastic but demand for commodity groups is price inelastic.

Li, Song and Witt (2004) examine the linear almost ideal demand system ((LAID), in both static and dynamic forms in the circumstance of international tourism demand. The result shows the dominance of the dynamic error correction LAIDS over the static counterpart, both suitable for theoretical restrictions and forecasting accuracy. The result calculates both long-run and short-run demand elasticity estimates. According to the results income elasticity estimates show that travelling to most main destinations in Western Europe seems to be a luxury for UK tourists in the long-run. UK tourists seem to be more responsive to price changes in the destinations in the long run than in the short run.

Song and Li (2012) discuss tourism demand modelling and forecasting, and how tourism demand be assessed. The study evaluates two measures in the circumstance of econometric modelling and the forecasting of tourism demand. The empirical research emphasises on demand for Hong Kong tourism by Australian residents, the UK and the USA using general-to-specific modelling approach. The results demonstrates that tourists' arrivals in Hong Kong are determined mainly by income of tourists and the tourism price in Hong Kong as compared to that of the tourist origin country. 
Syriopolos et al (1993) employ the Almost Ideal Demand System (AIDS) to estimate tourism expenditure allocation by US and West European countries among a range of Mediterranean destinations. The expenditure elasticities demonstrate considerable variations in tourism demand preferences between origin countries and between newly developing countries. The own and cross-price elasticity estimates indicate the significance of effective prices to determine the apportionment of expenditure among destinations.

Gatt and Falzon (2014) utilize AIDS, a model which depends on economic theory, to estimate the own-price and cross-price elasticity estimates in the Mediterranean countries. This is because the study determines the market share estimation amongst the seven Mediterranean countries. Greece-Spain, Greece-Portugal, Spain-Portugal and Italy-Turkey are substitute destinations, whereas Greece-Italy, Spain-Turkey, Portugal-Italy and Spain-Italy are complementary holiday destinations.

Song et al (2010) compare two measures of tourism demand, arrivals and expenditure of visitors in connection with econometric modelling and forecasting of tourism demand. Data on Hon Kong's tourism are utilised. It also to test the appropriateness of tourism demand modelling and forecasting. The result demonstrates that the arrival of tourists is to be affected by income of origin country and habit formation effect. However, expenditure of tourists is always affected by the prices of the destination in relation to tourists in the origin country.

De Mello (2005) uses a general form of the Dynamic AIDS (DAIDS) to analyse UK tourism demand for the destination of Portugal, Spain and France. Obtaining consistent information on how tourists apportion expenditure and how they adjust to equilibrium is of great interest for tourism analysis and policy formulation and implementation in the area of tourism demand. The main objective of the study has been to show that carefully built models do matter for the progress of research in the tourism demand analysis.

Fernandes et al estimate the elasticity of demand for inbound tourism with an intention to recognise the factors that impact their demand. Tourist arrivals, real per capita income, relative prices, and accommodation costs are tested for panel unit roots and panel co-integration is employed to determine the specification of the models used. The study observes that the determinants of elasticity estimates of demand for the entire panel are consistent with the theory.

Katafono and Gounder (2004) model the demand for tourism in Fiji. The study uses co-integration and error correction methods to build a tourism demand model for Fiji. The results show that both long-run and short run indicate that income of the major trading partners is positively related with tourism demand. This could be explained by the fact that increases in the long-term prices do not deter tourists.

Athanasopoulos and Hyndman (2006) use a regression to estimate important economic relationships for domestic tourism demand. They recognize as well the effect of world events such as the 2000 Sydney Olympics and the 2002 Bali Bombings on Australia's domestic tourism.

Sotiriadis and Varvaressos (2014) analyse the understanding of developing leisure tourism in Greece so as to have some important lessons for other tourism destinations. The study uses the technique of strategic analysis. This technique demonstrates the importance of tourism as an important economic activity and assesses the recent situation and structural problems of Greece as a destination. The result shows that Greek tourism could do better if there was a suitable tourism planning and reliable policy. Its main focus must be the sustainable development of destination.

Following Fujii et al (1985), earlier researches on travel demand were centred on single-equation models, where the demand for a particular type of travel was expressed as a function of its own price and income. The study comments that one key defect of the single-equation approach is that it cannot model the effect of a change in a particular region or destination on the demand for a visit to a different region or destination. The research analyses expenditure by visitors to Hawaii for six different categories of goods: food and drinks; lodging; recreation and entertainment; local transport; clothing and other. The results of the model provide empirical estimates of own, cross price and income elasticities of demand from a complete dataset on expenditure by visitors to a tourist destination. The analysis shows its usefulness as it evaluates the effects of policies on the pricing of tourism goods and services at a resort. 


\section{Method of the study}

\subsection{Research Design}

The data for this study was obtained by probability sampling in the context of a domestic tourism household panel surveys from 2012 to 2014 and secondary data from 2015 to 2016/2017 from Ghana Statistical Service. The data cover the ten (10) regions of Ghana.

\subsection{Stratification}

For the survey estimates to be precise and reliable, the country was stratified into the three ecological zones: coastal, forest and savannah. Within each zone, Enumeration Areas (EAs) were selected (2010 Ghana's Population and Housing Census National Sampling Frame).

\subsection{Sample Size and Allocation}

The study adopted a two-stage stratified random sampling design for choosing the sample. For the first stage, a sample of 20 EAs was selected using systematic sampling with probabilities proportional to size (Cochran, 2007). The second level of selection used systematic sampling of households from the original list of the households. Owing to the smallness of the sample size and to cover more households, twenty households were selected from each EA (United Nations, 2005).

\subsection{Data Collection}

The primary data gathered in 2012, 2013 and 2014 on tourism goods and services included accommodation, food and drinks, transport, recreation, cultural and sporting activities, shopping/non-consumables and other services. The three surveys were conducted separately in each year, using a questionnaire, and they were a face-to-face interview in the sampled households. A representative sample of about 1,586 adults aged 15 years and over within Ghana were involved in the three yearly surveys. The surveys were for adults but the study collected information on all adults and children who were part of the trip. The surveys were designed to be representative of all the people in Ghana. Respondents were asked whether they had taken tourism trips in Ghana that involved at least one night away from home or a same-day trip away from home. When such trips were identified, further questions were asked about a maximum of six trips - the most recent six trips - with a core set of questions for all six trips. Apart from the most recent six trips on which questions were asked, any additional trips were considered and recorded as such.

\subsection{Data Analysis}

In order to check for the completeness and accuracy of the data, manual editing was performed on all the questionnaires received from the field by data editors. Consistency checks of the data were carried out to further reduce errors after which it was captured. Cs-pro was used for the data capture while Software R was employed to estimate dynamic linear AIDS models. Own-price elasticities, cross-price elasticities and expenditure/income elasticities of tourism products purchased by domestic tourists (accommodation, food and drinks, transport, recreation, culture and sporting activities, shopping and others) were calculated using Linear Almost Ideal Demand System (LAIDS) (static and dynamic) models for Ghana.

\subsection{Static Model}

\subsubsection{Static Linear Almost Ideal Demand Model (Long-run)}

The AIDS model has solely static functional form, indicating that long-run consumer behaviour is always in equilibrium and there is no difference between long-run and short-run behaviour. The long-run AIDS can be seen as an extension of the Working-Leser model (Working, 1943; Leser, 1963), where the expenditure share for commodity i relates the logarithms of prices and total real expenditure as stated as follows:

$w_{i}=\alpha_{i}+\sum_{i} \gamma_{i j} \log P_{j}+\beta_{i} \log \left(\frac{x}{p}\right)+\epsilon_{i}$ [Deaton and Muellbauer, 1980]

where $w_{i}$ is a budget or expenditure share, $\mathbf{F}_{\mathrm{j}}$ is the price of $\mathrm{j}^{\text {th }}$ commodity, $\mathrm{n}$ is the number of items (tourism goods and services), $\mathrm{x}$ is the overall expenditure on tourism products, 
$\alpha_{1}$ measures the average share of product $i_{1} \gamma_{i j}$ measures the effect on the share of product $i$, (due to a $1 \%$ change in the price of commodity $\mathrm{j}$ ) due to an increase in the relative price of product $\mathrm{j}$, at constant expenditure. $\beta_{i}$ measures the effect on the budget share of a good or service i given an increase in the real expenditure per capita. $\mathrm{X} / \mathrm{P}$ is real expenditure, $\mathrm{P}$ is the price index defined as in equation (3.1) and $\boldsymbol{\epsilon}_{i}$ is the disturbance term, $\epsilon_{i} \sim N\left(\mathrm{C}_{i} \sigma_{i}^{2}\right)$.

A geometric price index which has been widely used is the Stone's price index, and is stated below:

$$
\mathrm{P}^{*}=\prod_{i}^{w i} p_{i}
$$

Taking logarithms of both sides gives:

$\log p^{k}=\Sigma_{i}$ wi $\log p i$

(Statistics Norway, 2013)

For the static model to be linear, Deaton and Muellbauer (1980), suggested that the price index P is replaced with Stone's price index $P^{*}$ which takes the form, $\ln \mathrm{P}^{*}=\sum_{i}^{n} w_{i}^{B} \ln P_{i}$, where $w_{i}^{B}$ is the budget share, wi, of goods or services in the base year.

$w_{i}=\alpha_{i}+\sum_{i} \gamma_{i j} \log P_{i}+\beta_{i} \log \left(\frac{x}{p^{*}}\right)+\epsilon_{i}$

\subsubsection{Dynamic Linear Almost Ideal Demand System Model (Short-run)}

$$
\Delta w_{i}=\psi_{i} \Delta W_{i t-1}+\sum \gamma_{i j} \Delta \ln P_{i}+\beta_{i} \Delta \ln \left(\frac{x}{n^{*}}\right)+\lambda_{i} V_{i t-1}+\epsilon_{i}
$$

Where $\Delta$ is the first-difference operator, and $U_{i t-1}$ are the lagged estimated residuals obtained from the long-run static model in equation (3.1), and $W_{i t-1}$ is the lagged budget share to capture consumption habit and inventory adjustments. The coefficient, $\lambda$, captures the speed of adjustment towards the long-run equilibrium at time $\mathrm{t}-1$, and it should be significant and negative, and $\varepsilon_{i}$ is the disturbance term, $\psi$ is introduced to measure the effect of consumption habit, including habit persistence and inventory adjustments (Yang et al, 2010). $\gamma, \beta$ and $\psi$ aro parameters to be estimated and $\mathrm{i}=12, \ldots, \mathrm{n}, \mathrm{j}=1,2, \ldots, \mathrm{n}$ and $\mathrm{t}=2, \ldots, \mathrm{T}$.

\subsection{Restrictions on the Parameters of the AIDS Model}

To comply with economic theory, the following restrictions should apply on the parameters of the static and dynamic AIDS models: adding up; homogeneity; symmetry; and negativity.

a. Adding-up restrictions:

- $\sum_{i-1}^{n} \alpha_{i}=1$;

- $\sum_{i=1}^{n} \beta_{i}=0$;

- $\quad \sum_{i=1}^{n} \gamma_{i j}=n$, for all $\mathrm{j}$;

b. Homogeneity implies $\Sigma_{j=1}^{n} \gamma_{i j}=0$, forall $i_{\text {, }}$ which is based on the assumption that a proportional increase in all prices and expenditure does not affect demand; this means, decisions to consume are made on the basis of relative prices and income alone.

c. Symmetry implies $\gamma_{i j}=\gamma_{j i}$ for all $\mathrm{j}$; that takes consistency of consumer selection or choices into account.

d. Negativity is based on the laws of demand which means that all compensated own-price elasticities must be negative, where the adding-up restriction is satisfied by leaving out one equation from the estimation.

\subsection{Calculation of Demand Elasticities}

The elasticity values are worked out or calculated using the static and dynamic models' estimates as follows:

i. Expenditure or income elasticities:

$$
\varepsilon_{i}=\frac{\beta_{i}}{w_{i}}+1
$$

$\varepsilon_{i i}=\frac{\gamma_{i i}}{w_{i}}-\beta_{i}-1$

Uncompensated own-price elasticities:

iii. Uncompensated cross-price elasticities:

$\varepsilon_{i j}=\frac{\gamma_{i j}}{w_{i}}-\beta_{i} \frac{w_{i}}{w_{i}}$ 


$$
\begin{aligned}
& \text { iv. Compensated own-price elasticities: } \\
& \begin{array}{c}
\dot{\varepsilon}_{i i}=\frac{y_{i i}}{w_{i}}+w_{i}-w_{j} \\
\text { v. } \quad \text { Compensated cross-price elasticities }
\end{array} \\
& \dot{\varepsilon}_{i j}=\frac{\gamma_{i i}}{w_{i}}+w_{j}
\end{aligned}
$$

\subsection{National Estimates}

The aggregate demand for domestic tourism by Ghanaians and non-Ghanaians resident in Ghana is estimated as follows:

$X^{0 \mathrm{r}}=\ln \left(\frac{\text { Total national expenditure }\left(2 X_{i}^{n}\right) / \text { /Shana's population }}{p^{*}}\right)$

$X^{\mathrm{ur}}=$ real per capita expenditure for the country.

$\mathrm{Xi}=$ expenditure on accommodation, food \& drinks, transportation, recreation, culture \& sporting activities, shopping/non-consumable and others.

$P_{\mathrm{i}}$ is the price of good or service $\mathrm{i}$, hence $\mathrm{P}_{2}-\ln (C P I), \mathrm{i}=(1,2, \ldots, 6)$. Prices of the six commodity groups: accommodation, food $\&$ drinks, transportation, recreation, culture $\&$ sporting activities, shopping and others

$C P I_{i}=$ is the Consumer Price Index of each of the 6 commodity groups, $i=(1,2, \ldots, 6)$.

\subsection{Some Data Variable Specification}

Since data on the prices for each category of expenditure were not available, the prices were proxied by the consumer price indices of the Ghana Statistical Service. The proxy used for prices of accommodation was the CPI subcategory for accommodation. Food and drinks was the CPI subcategory for food and non-alcoholic beverages. Transport prices was the CPI subcategory for transport. Recreation, culture and sporting activities prices was the CPI subcategory for recreation and culture. Shopping prices was the CPI subcategory for clothing and footwear and others prices was the CPI subcategory for miscellaneous services.

\subsection{Econometric Methods}

To estimate the dynamic model, the properties of the data are examined to ascertain whether the variables are integrated of the same order. Using the data, the Augmented Dickey Fuller (ADF) unit root tests suggest that all the variables are integrated of order $0, \mathrm{I}(0)$. Those of order $1, \mathrm{I}(1)$ were differenced to assume the order $0, \mathrm{I}(0)$ integration. Secondly, the long-run equilibrium relationship among the variables is examined by using the EngleGranger (1987) co-integration tests on the residuals from the static AIDS model. The co-integration relationship could not be rejected using Engle-Granger (1987) approach at the 5\% significance. The results show that the residual variables are stationary and therefore are co-integrated and thus there is a long-run relationship for each tourism good or service. The results indicate that the dynamic AIDS model has been established to examine the short-run adjustments or dynamics. Hence both the long-run and short-run models could be estimated.

Zellner (1962) iterative method for seemingly unrelated regressions (SUR) is used for the analysis. Because the sum of all expenditure shares in the LAIDS model is equal to 1 , the residuals variance-covariance matrix will be singular, because the adding up constraint $\left(\sum_{i}^{n} W_{i}\right)$ implies a singular variance-covariance matrix. To avoid this situation, we delete one of the equations (others) from the system and estimate the remaining five equations. Homogeneity and symmetry conditions $\left(\gamma_{i j}-\gamma_{j i}\right)$ are strictly adhered to before the system is being estimated. The negativity, that is, the values of own-price elasticities are observed to be negative, following the Slutsky's matrix sign. Zellner's estimates have similar asymptotic properties as the maximum likelihood (ML) estimates and they are not different from the selection of the omitted equation (Barten, 1969). 


\section{Analysis}

The results of the study and the analysis of the collected data from 2012 to 2017 have been presented in this section. To explain the determinants of the domestic tourism demand, the study utilized the AIDS model. The linear almost ideal demand system model (static and dynamic) is used in analysing the economic factors which underlie the demand for tourism goods and services in Ghana by domestic tourists.

\subsection{First-stage Parameter Estimates from Static and Dynamic LAIDS Models}

Table 1 reports on the static model for the first-stage estimates of the parameters $\alpha_{i} \gamma_{s} \beta$ for the country's domestic tourists' consumption of tourism products. However, $\alpha_{i}{ }^{\prime} s$ are practically of little interest. $\beta_{i}{ }^{\prime} s$ determine whether the good or service in question is a luxury or necessity ( Deaton, A \& Muellbauer, J. 1980 and Statistics Norway, 2013). The overall statistical fit of the model is satisfactory. From Table 1, the estimates of $\beta$ classify recreation, culture and sporting activities as a necessity and the rest as luxuries. A proportional increase in prices and expenditure will increase expenditure on accommodation, food and drinks and transportation, and decrease expenditure on recreation, culture and sporting activities, shopping and other services. Recreation, culture and sporting activities' group is a necessity group while the remaining five are luxury groups.

Table 1: First-stage national parameter estimates from static LAIDS model

\begin{tabular}{lccrrrrrr}
\hline EQUATION & $\alpha_{i}$ & $\gamma_{i 1}$ & $\gamma_{i 2}$ & $\gamma_{i 3}$ & $\gamma_{i 4}$ & $\gamma_{i 5}$ & $\gamma_{i 6}$ & $\beta_{i}$ \\
\hline ACC & 0.193 & -0.013 & 0.021 & -0.316 & 0.121 & 0.013 & 0.174 & 0.013 \\
FND & 0.196 & & -0.040 & 0.343 & -0.126 & -0.081 & -0.117 & 0.114 \\
TRA & 0.184 & & & -0.008 & 0.056 & 0.259 & -0.334 & 0.032 \\
RCS & 0.185 & & & & 0.090 & -0.271 & 0.120 & -0.175 \\
SHO & 0.183 & & & & & 0.184 & -0.104 & 0.003 \\
OTH & 0.059 & & & & & & 0.261 & 0.013 \\
\hline
\end{tabular}

Source: Study data $2012-2014$ and Ghana Statistical Service

From Table 2, for the dynamic LAIDS model, there are some similarities among the estimated parameter values. There are two luxuries (food and drinks, and other services) and four necessities (accommodation, transportation, recreation, culture and sporting activities and shopping). Table 2 shows further that the estimated parameters of the error correction terms, $\lambda_{l}$, possess the correct signs, that is, they are negative and significant. The shopping and transportation error correction terms,-1.116 and -1.104 respectively, indicate that domestic tourists in Ghana are able to adjust shopping and transportation consumption to long-run equilibrium quicker than the remaining four products (Motallebi et al, 2013).

The coefficients of the lagged share variable in the short-run (dynamic) LAIDS model show a pattern of consumption habit. Habit means that the utility functions of the consumers are influenced by past purchases, which results in influencing present purchases, (Wu et al 2011). Five of the coefficients are positive and one being negative for all the six commodities. The positive coefficients for food and drinks (0.105), transport $(0.223)$, recreation, culture and reporting activities (0.129), shopping $(0.198)$ and other $(0.095)$ indicate that domestic tourists have habit persistence for these commodities. The negative sign for accommodation $(-0.022)$ indicates a less habit persistence effect exists for consumers. 
Journal of Tourism, Hospitality and Sports

www.iiste.org

ISSN (Paper) 2312-5187 ISSN (Online) 2312-5179 An International Peer-reviewed Journal DOI: 10.7176/JTHS

Vol.40, 2019

Table 2: First-stage parameter estimates from dynamic LAIDS model

\begin{tabular}{lccccccccccc}
\hline EQUATION & $\gamma_{i 1}$ & $\gamma_{i 2}$ & $\gamma_{i 3}$ & $\gamma_{i 4}$ & $\gamma_{i 5}$ & $\gamma_{i 6}$ & $\beta_{i}$ & $\lambda_{i}$ & $\psi_{i}$ & R-sq & DW \\
\hline ACC & \multirow{2}{*}{0.003} & -0.003 & 0.011 & -0.003 & -0.020 & 0.012 & -0.009 & -1.002 & -0.022 & 0.521 & 1.959 \\
FAD & & 0.007 & -0.002 & -0.005 & -0.004 & 0.007 & 0.015 & -1.050 & 0.105 & 0.427 & 1.982 \\
TRA & & & 0.003 & -0.003 & 0.009 & -0.019 & -0.013 & -1.104 & 0.223 & 0.518 & 1.926 \\
RCS & & & -0.002 & 0.001 & 0.013 & -0.005 & -1.047 & 0.129 & 0.492 & 1.945 \\
SHO & & & & 0.019 & -0.006 & -0.012 & -1.116 & 0.198 & 0.629 & 1.931 \\
OTH & & & & & -0.007 & 0.024 & -1.048 & 0.095 & 0.468 & 1.952 \\
\hline
\end{tabular}

Source: Study data 2012 - 2014 and Ghana Statistical Service

\subsection{National Estimates of Long-run and Short-run Uncompensated Own-price and Cross-price Elasticities}

Nationally, regarding long-run, for the overall ranking, it is observed that the demand for food and drinks is relatively the most price elastic (-1.126), followed by other services (-1.075), then shopping (-1.067), accommodation (-1.038) and transportation (-1.004), hence an increase in their prices will result in proportionate decrease in the their quantities demanded and hence decrease their consumption to decrease revenue, while the demand for recreation, culture and sporting activities (-0.917) is price inelastic. For the longrun, of the six commodities, nationally, food and drinks is the most expensive, followed by other services, shopping, accommodation, transportation and recreation, culture and sporting activities. Nationally, regarding short-run, for the overall ranking, it is observed that the demand for food and drinks (-1.039) is relatively the most price elastic, followed by other services (-1.014), meaning they behave as normal luxury products, indicating that the consumption of these goods and services is sensitive to prices. This suggests that a rise in prices of these commodities would result in more than proportionate decrease in their quantities demanded and reduce revenue to suppliers and the nation. The demand for recreation, culture and sporting activities $(-0.978)$, accommodation (-0.957), shopping (-0.871) and transportation (-0.728) is price inelastic. This indicates that a rise in prices of these commodities will result in less than proportionate decrease in their quantities demanded and hence increase revenue.

Nationally, regarding short-run, for the overall ranking, it is observed that the demand for food and drinks ($1.039)$ is relatively the most price elastic, followed by other services (-1.014), meaning they behave as normal luxury products, indicating that the consumption of these goods and services is sensitive to prices. This suggests that a rise in prices of these commodities would result in more than proportionate decrease in their quantities demanded and reduce revenue to suppliers and the nation. The demand for recreation, culture and sporting activities (-0.978), accommodation (-0.957), shopping (-0.871) and transportation (-0.728) is price inelastic, indicating that a rise in prices of these commodities would result in less than proportionate decrease in their quantities demanded and hence increase revenue.

For the short-run, of the four commodities, nationally, food and drinks is relatively the most expensive, followed by other services then recreation, culture and sporting activities, accommodation and shopping. To complement the static model by the dynamic model, the elasticity estimates show that these four commodities, food and drinks, other services, recreation, culture and sporting activities, and accommodation have their elasticity around unity, and hence have fairly elastic demand, suggesting that the government of Ghana and the tourism practitioners should be careful about their pricing and taxation policies. If care is not taken about their pricing by tourism and tourism related industries, the prices of these four tourism goods and services will increase, and domestic tourists will decrease their consumption which will affect the domestic tourism industry. However, the demand for shopping and transportation is price inelastic and hence an increase in their prices will result in less than proportionate decrease in their quantities demanded and hence increase their consumption rapidly to increase revenue. For the four tourism goods and services whose price elasticities are relatively unitary suggest that they could need government subsidy. 
The short-run uncompensated cross-price elasticities show substitutability and complementarity. Out of 15 pairs of the uncompensated cross-price elasticities at the upper triangle of the panel, six of them are significant, four are complements and two are substitutes. Similarly, the short-run elasticities show that the cross-price effects are relatively low. However, a price rise in one good generally has some effects on all other goods and services.

Nationally, for the short-run, using uncompensated cross-price elasticities, when the price of accommodation increases by $10 \%$, the quantity demanded of transport decreases by $0.97 \%$ and vice versa. Similarly, when the price of recreation, culture and sporting activities increases by $10 \%$, the quantity demanded of other services increases by $0.99 \%$ and vice versa to increase revenue, but the demand for shopping will decrease by $0.09 \%$ (Table 3).

Table 3: Estimates of long-run and short-run uncompensated own and cross-price elasticities of Ghanaian Tourism Goods and Services

\begin{tabular}{|c|c|c|c|c|c|c|}
\hline Quantity/Price & $\mathrm{ACC}$ & FAD & TRA & RCS & $\mathrm{SHO}$ & $\mathrm{OTH}$ \\
\hline \multicolumn{7}{|l|}{ Long-run } \\
\hline $\mathrm{ACC}$ & $-1.038 * * *$ & $-0.072 *$ & $-0.133 * *$ & 0.116 & 0.019 & 0.185 \\
\hline FAD & $-0.003 *$ & $-1.126 * * *$ & $0.356 * *$ & -0.165 & $-0.413 * * *$ & 0.117 \\
\hline TRA & $-0.030 * *$ & $0.426^{* *}$ & $-1.028 * * *$ & 0.01 & 0.3 & -0.389 \\
\hline RCS & 0.16 & -0.129 & 0.046 & $-0.917 * * *$ & -0.257 & 0.213 \\
\hline $\mathrm{SHO}$ & 0.023 & $-0.406 * * *$ & $0.286^{*}$ & $-0.262 *$ & $-1.067 * * *$ & $0.094^{*}$ \\
\hline OTH & 0.193 & 0.157 & -0.361 & 0.172 & $0.097 *$ & $-1.075^{* *}$ \\
\hline \multicolumn{7}{|l|}{ Short-run } \\
\hline $\mathrm{ACC}$ & $-0.957 *$ & $-0.041 *$ & $-0.097 * *$ & -0.031 & -0.160 & $0.104^{*}$ \\
\hline FAD & $-0.034 *$ & $-1.039 * * *$ & $-0.024 * * *$ & -0.037 & $-0.020 * * *$ & 0.06 \\
\hline TRA & $-0.066^{*}$ & $-0.024 * * *$ & $-0.728 * * *$ & -0.016 & -0.072 & -0.124 \\
\hline RCS & -0.028 & -0.042 & -0.019 & $-0.978 * * *$ & $-0.009 *$ & $0.099 *$ \\
\hline $\mathrm{SHO}$ & $-0.110 *$ & $-0.009 * * *$ & 0.071 & $0.003 *$ & $-0.871 * * *$ & -0.028 \\
\hline OTH & $0.103 *$ & 0.055 & -0.110 & $0.087 *$ & -0.053 & $-1.014 * * *$ \\
\hline
\end{tabular}

Notes: $* * *, * *$ and $*$ indicate $1 \%, 5 \%$ and $10 \%$ significant levels respectively

Source: Study data $2012-2014$ and Ghana Statistical Service

\subsection{Estimates of Long-run and Short-run Compensated Own-price and Cross-price Elasticities}

To have a comprehensive understanding of the competition relationship among tourism goods and services, the compensated cross-price elasticities are calculated and reported in Table 4. According to Table 4, positive price elasticity between two tourism goods and services denotes substitutability and a negative value denotes complementarity. In all, there are 15 pairs of cross-price elasticities among tourism goods and services. In the long-run, five of the 15 pairs of compensated cross-price elasticities at the upper triangle of the panel are significant. All of them are positive, indicating the presence of substitution relationships between the six consumption categories. The extent of substitutability is highest between food and drinks and transportation, followed by between transportation and shopping, between accommodation and other services, accommodation and recreation, culture and sporting activities, and between accommodation and transportation. For instance, when the price of accommodation is increased by $10 \%$ the quantity of other services demanded increases by $3.78 \%$ and vice versa; when the price of food and drinks increases by $10 \%$, the quantity demanded of transport services increases by $5.61 \%$.

In the short-run, six of the 15 pairs of the compensated cross-price elasticities at the upper triangle of the panel are significant. Three (3) are positive and three are negative. Those positive indicate substitutability and the 
negatives indicate complementarity, meaning, these three are bought together. The substitutes are accommodation versus transportation; food and drinks versus transportation; and recreation, culture and sporting activities versus shopping. The complements are accommodation versus recreation, culture and sporting activities; food and drinks versus shopping; and recreation, culture and sporting activities versus others.

For compensated cross-price elasticities, for example, in the short-run, the tourists' demand for accommodation in the country is more responsive to price changes in transportation than is their demand for transportation in response to price changes in accommodation, related with cross-price elasticities of 0.212 and 0.065 , respectively. This indicates that if the average transport fare increases by $10 \%$, then domestic tourists in Ghana are likely to spend $2.12 \%$ more on accommodation, but if the average price of accommodation increases by $10 \%$, the domestic tourists in Ghana will spend only $0.65 \%$ on transportation.

Table 4: Estimates of long-run and short-run compensated own and cross-priceelasticities of Ghanaian tourism goods and services

\begin{tabular}{|c|c|c|c|c|c|c|}
\hline Quantity/Price & $\mathrm{ACC}$ & FAD & TRA & $\mathrm{RCS}$ & $\mathrm{SHO}$ & OTH \\
\hline \multicolumn{7}{|l|}{ Long-run } \\
\hline $\mathrm{ACC}$ & $-0.825 * * *$ & 0.231 & $0.250 *$ & $0.296 * *$ & 0.216 & $0.378 *$ \\
\hline FAD & 0.216 & $-0.810 * * *$ & $0.561 * * *$ & 0.037 & -0.192 & 0.333 \\
\hline TRA & $0.161 *$ & $0.639 * * *$ & $-0.836 * * *$ & 0.194 & $0.502 * * *$ & -0.193 \\
\hline $\mathrm{RCS}$ & $0.321 * *$ & 0.043 & 0.197 & $-0.693 * * *$ & -0.094 & 0.371 \\
\hline $\mathrm{SHO}$ & 0.214 & -0.202 & $0.464 * * *$ & -0.086 & $-0.627 * * *$ & 0.282 \\
\hline $\mathrm{OTH}$ & $0.384 *$ & 0.36 & -0.183 & 0.348 & 0.29 & $-1.054 * *$ \\
\hline \multicolumn{7}{|l|}{ Short-run } \\
\hline $\mathrm{ACC}$ & $-0.815^{*}$ & 0.097 & $0.212 *$ & $-0.097 *$ & -0.014 & -0.260 \\
\hline FAD & 0.094 & $-0.515 * * *$ & $0.144 * * *$ & -0.086 & $-0.146 * * *$ & 0.209 \\
\hline TRA & $0.065^{*}$ & $0.109 * * *$ & $-0.748 * * *$ & -0.107 & 0.240 & -0.027 \\
\hline $\mathrm{RCS}$ & $-0.102 *$ & 0.093 & 0.122 & $-0.792 * *$ & $0.160^{*}$ & $-0.251^{*}$ \\
\hline $\mathrm{SHO}$ & -0.010 & $-0.116 * * *$ & 0.200 & $0.117^{*}$ & $-0.611 * * *$ & -0.112 \\
\hline $\mathrm{OTH}$ & 0.230 & 0.186 & 0.027 & $-0.208^{*}$ & -0.113 & $-0.931 * * *$ \\
\hline
\end{tabular}

Notes: $* * *, * *$ and $*$ indicate $1 \%, 5 \%$ and $10 \%$ significant levels respectively

Source: Study data 2012 - 2014 and Ghana Statistical Service

\subsection{Estimates of uncompensated own-price elasticities and expenditure/income elasticities}

For the long-run, only recreation, culture and sporting activities is price inelastic, with a coefficient of -0.917 , while the remaining products reveal price elastic demand, with elasticities ranging from -1.028 to -1.126 . For the short-run, food and drinks and other services reveal price elastic demand, while accommodation, transport, recreation, culture and sporting activities and shopping reveal price inelastic demand, with elasticities ranging from -0.728 to -0.978 .

As usual, all the expenditure/income elasticities for both long-run and short-run are positive, indicating that they are normal goods. Regardless of time horizon, and in terms of long-run, the groups of accommodation, food and drinks, transportation, shopping/non-consumables and others are luxury tourism products, while the group of recreation, culture and sporting activities is a necessity. The results show that all the short-run expenditure elasticities are smaller than that of long-run elasticities (Table 5).

A comparison of income elasticities derived from long-run and short-run show substantial differences in the sizes of elasticities of demand. For the long-run, income elasticities show considerable differences, ranging from 0.918 (shopping) to 1.039 (recreation, culture and sporting activities). Income elasticities for accommodation (1.001), food and drinks (1.038) and other (1.039) are greater than unity, indicating that a rise in tourists' 
expenditure could result in a rise in the demand for these goods and services. While income elasticities for transportation (0.991), shopping (0.918) recreation, culture and sporting activities (0.977) are below unity which indicate that an increase in the income of domestic tourists will result in increase in the demand for these products, but at lower proportions.

For the short-run, income elasticities show variations, and range from 0.897 to 1.061 . Recreation, culture and sporting activities, shopping and other services and transportation are above unity and hence they are normal luxury goods. However, income/expenditure elasticities for accommodation and food and drinks are below unity, indicating that a rise in tourists' expenditure could result in an increase in the demand for these goods and services in the country, but at a lower proportion.

Table 5: National estimates of the uncompensated own-price and expenditure/ income elasticities of Ghanaian tourism goods and services

\begin{tabular}{|c|c|c|c|c|}
\hline \multirow[b]{3}{*}{ Commodity } & \multicolumn{4}{|c|}{ Uncompensated own-price } \\
\hline & \multicolumn{2}{|c|}{ elasticities } & \multicolumn{2}{|c|}{ Expenditure elasticity } \\
\hline & Long-run & Short-run & Long-run & Short-run \\
\hline $\mathrm{ACC}$ & $-1.038 * * *$ & $-0.957 * * *$ & $1.001 * * *$ & $0.897 * * *$ \\
\hline FAD & $-1.126 * * *$ & $-1.039 * * *$ & $1.038 * * *$ & $0.945 * * *$ \\
\hline TRA & $-1.028 * * *$ & $-0.728 * * *$ & $0.991 * * *$ & $1.061 * * *$ \\
\hline $\mathrm{RCS}$ & $-0.917 * * *$ & $-0.978 * * *$ & $0.977 * * *$ & $1.018^{* * *}$ \\
\hline $\mathrm{SHO}$ & $-1.067 * * *$ & $-0.871 * * *$ & $0.918 * * *$ & $1.026^{* * *}$ \\
\hline $\mathrm{OTH}$ & $-1.075 * * *$ & $-1.014 * * *$ & $1.039 * * *$ & $1.028 * * *$ \\
\hline
\end{tabular}

Source: Study data $2012-2014$ and Ghana Statistical Service

\section{Discussions}

This section discusses the findings drawn from the study. The visitor consumption expenditure data used for the study cover a period of 2012 to 2017, where primary expenditure data (panel data) cover 2012 to 2014 and secondary expenditure data from 2015 to 2016/2017 from the Ghana Statistical Service. The study shows that shopping error correction term,-1.116, indicates that domestic tourists in Ghana are able to adjust shopping consumption to long-run equilibrium quicker than the remaining five products (Motallebi et al, 2013).

For the short-run, the results show that, over all, the demand for tourism goods and services in Ghana is price inelastic, and their elasticities range from 0.728 ( transportation) to 1.039 ( food and drinks) in absolute value. This in line with studies done in Australia by Song et al (2013) and Divisekera (2007), where domestic tourists in Australia's demand for tourism goods and services is price inelastic. It is also in line with a study by Sadeghi et al (2007) in Iran on 'Demand of Domestic Tourism' where the demand for tourism goods and services is price inelastic.

Should government of Ghana or private investors put up industries in the country, then the construction of transport enterprises, shopping centers, accommodation facilities and recreation, culture and sporting facilities should be given priority attention among the variables. Generally, with respect to own-price elasticities, Ghanaian domestic tourists are more responsive to price changes in the long-run than in the short term

A comparison of income elasticities derived from long-run and short-run show substantial differences in the sizes of the elasticities of demand. For long-run, income elasticities demonstrate differences which range from 0.918 (shopping) to 1.039 (other services). Income elasticities for other services (1.039), food and drinks (1.038) and accommodation (1.001) are greater than unity, indicating, a rise in tourist budgets would cause an increase in demand for these goods and services.

For the short-run, the results show that, overall, the demand for tourism goods and services by tourists in Ghana are fairly income elastic, with their elasticities which range from 0.897 (accommodation) to 1.061 (other services). Income elasticities for recreation, culture and sporting activities (1.018) shopping (1.026), other services (1.028) and transport (1.061) are above unity and hence they behave as normal luxury goods. This 
means that a $10 \%$ increase or decrease in the tourism budgets of Ghanaian tourists would lead to $10.18 \%$, $10.26 \%, 10.28 \% 10.61 \%$ increase or decrease in their expenditure on recreation, culture and sporting activities, shopping, other services and transport respectively. However, income elasticities for accommodation and food and drinks are relatively income inelastic. This implies that these goods and services are normal necessity goods. An increase in tourist budgets in Ghana will result in an increase in the demand for these commodities in Ghana, but in smaller proportions of money would be expended on them. The implication of the findings is that policy makers and tourism practitioners should pay more attention to the expansion of these six commodities. The results are in line with studies conducted by Deaton, 1988, where the income elasticity for education and transport is 1.94, luxury, food and health services are necessity while the rest have income elasticities greater than unity. It is also in line with Divisekera (2007), where domestic tourists in Australia's demand for tourism goods and services is income elastic and that of Sadeghi et al (2007) in Iran's demand for tourism goods and services is income elastic.

For cross-price elasticities, for national elasticities, the level of substitution effect differs between a pair of expenditure categories. In actual fact, the substitution effect appears to be moderately strong for each pair of expenditure categories. For compensated cross-price elasticities, for example, in the long-run, the tourists' demand for accommodation in Ghana is more responsive to price changes in transportation than is their demand for transportation in response to price changes in accommodation, related with cross-price elasticities of 0.250 and 0.161 , respectively. This indicates that if the average transport fare increases by $10 \%$, then domestic tourists in Ghana are likely to spend $2.50 \%$ more on accommodation, but if the average price of accommodation increases by $10 \%$, the domestic tourists in Ghana will spend only $1.61 \%$ on transportation (Table 4).

\section{Conclusion}

An estimation of the price and income/expenditure elasticities of demand for Ghanaian tourism products using both static and dynamic Linear Almost Ideal Demand System (LAIDS) models has been made in Ghana. Domestic tourists' expenditure patterns in Ghana were being examined. This was achieved by estimating two demand systems. The static and dynamic LAIDS models examined the total tourist demand for tourism products in Ghana; i.e. the system of equations provided parameters of demand regarding Ghana. The demand parameters were estimated for the six categories or groups of tourism goods and services: accommodation; food and drinks; transportation; recreation, culture and sporting activities; shopping/non-consumables and others. The expenditure data used for the study cover a period of 2012 to 2017.

Nationally, for the static model, the studies show that, in general, demands for tourism products in Ghana are price elastic. This is because the elasticity estimates of most variables are above unity. For the static model (long-run), nationally, the estimates of the uncompensated own-price elasticities show that for the overall ranking, the demand for food and drinks is the most price elastic, followed by other services, then shopping, accommodation and transportation while recreation, culture and sporting activities is fairly price inelastic.

According to Song et al (2011), the dynamic AIDS model reflects the economic system more accurately than the static AIDS model. Hence, nationally, the results regarding dynamic model (short-run), the estimates of the uncompensated own-price elasticities show that for the overall ranking, the demand for food and drinks is comparatively the most price elastic, followed by other services, then recreation, culture and sporting activities, accommodation, shopping, and transportation. Hence, the results show that, over all, the tourists' demand for tourism products purchased by tourists in Ghana is price inelastic, with their elasticities stretching from 0.728 (transportation) to 1.039 ( food and drinks) in absolute terms.

According to Gujarati et al (2009), short-run price or income elasticity estimates are generally smaller (in absolute terms) than the corresponding long-run elasticity estimates. Expenditure elasticity estimates demonstrate that all the tourism products are normal goods and services. For expenditure/income elasticities, in the short-run, the results show that generally, the tourists' demand for tourism products purchased by tourists in Ghana is income elastic, with their elasticities stretching from 0.897 (accommodation) to 1.061(transportation).

Similarly, the magnitudes of income elasticities with respect to the two models are similar. For, instance, income elasticities for food and drinks and other services are above unity, while income elasticities for recreation, culture and sporting activities and accommodation are around unity for both models. These disparities in demand reflect the differences in preference of domestic tourists in Ghana. 
Nationally, the estimates of the long-run compensated own-price elasticities are below unity, except other services, and for the overall ranking, other services is relatively the most price elastic, followed by recreation, culture and sporting activities, transportation, accommodation, food and drinks and shopping. The estimates of the short-run compensated own-price elasticities are not different. Elasticity estimates of the commodity groups are below unity, and for the overall ranking, other services is relatively the most price elastic, followed by accommodation, recreation, culture and sporting activities, transportation, shopping and food and drinks.

For compensated cross-price elasticities, for example, in the short-run, the tourists' demand for accommodation in the country is more responsive to price changes in transportation than is their demand for transportation in response to price changes in accommodation (Table 4).

By the dynamic models, the estimates show that these six groups of tourism goods and services such as recreation, culture and sporting activities, accommodation, shopping and transportation have their price elasticities around unity, while groups like food and drinks and other services have their price elasticities above unity, suggesting that the government of Ghana and the tourism practitioners should be careful about the above bundle of tourism products of their pricing and taxation policies. If care is not taken about their pricing, the prices of these bundle of tourism goods and services will rise, and domestic tourists will decrease their consumption rapidly and this will affect the domestic tourism industry. The findings further imply that policy makers and tourism practitioners should pay more attention to the expansion of goods such as transport and other services which behave as luxury products.

Ghana's domestic tourists' demand for goods and services has been modelled, but there are some limitations of the study that should be brought to the notice of researchers for redress in future studies. Firstly, there was lack of tourism expenditure data, and hence the study used 2012 to 2014 as primary data and 2015 and 2016/2017 as secondary data from the Ghana Statistical Service.

Secondly, the data covered some kinds of travels or trips, including funerals; leisure, recreation and holidays; visiting friends and relatives; business and professionals; health treatment; religion/pilgrimage, education/training; and shopping. It can be concluded that the elasticity estimates would not reveal the actual preferences of domestic tourists. The reason being that the demands by professional and business tourists will distort the real price or income responsiveness of tourists, since government institutions such as Metropolitan, Municipality and District Assemblies (MMDA's), Ministries, Departments and Agencies (MDA's) and some private institutions sponsor such trips for their employees. Future research should focus on more disaggregation like holiday tourists, sports tourists, religious tourists, business tourists, professional tourist, etc.

Thirdly, the inclusion of these two segments of tourists, funeral tourists and VFR (visiting friends and relatives') tourists could influence the demand for tourist accommodation. The cause is that a great number of these two segments stay with their friends' and relatives' residences during tourism activities rather than staying in hotels. For future research the focus should be on more disaggregation like funeral tourists, visiting friends, visiting relatives, and narrow the aggregation of the categories of tourism goods and services, like recreation, culture, sports, food, drinks or beverages as categories of expenditure.

Fourthly, the study focused on only the destination of domestic tourists and not on the origin of domestic tourists. The ideal situation to model the tourist demand is to take the two into consideration. This came about due to the stratification of Ghana into three zones. Owing to this, the domestic tourists are not distinguished by the origin of region. For future study, domestic tourists should be distinguished by the region of origin and destination to make the modelling of domestic tourist demand an ideal one.

\section{References}

Athanasopoulos, G. and Hyndman, R. J. (2006), 'Modelling and Forecasting Australian Domestic Tourism'. Tourism Management 29, 19-31

Bank of Ghana (2007), “The Tourism Industry and the Ghanaian Economy”, Accra, Ghana

Cleck Cai, L.A; Hu, B. and Feng, R. (2002), "Domestic Tourism Demand in China's Urban Centers'. Empirical Analyses and Marketing Implications. Journal of Vacation Meetings 8(1), 64 - 71. 
Cochran,W. G. (2007). Sampling Techniques

Coenen, M.(2003), “'A Study of the Demand for Domestic Tourism by Swedish Households'. A Journal.

De Mello, M. (2001), “Theoretical and Empirical Issues in Tourism Demand Analysis'”. PhD thesis. University of Nottingham. Nottingham

De Mello, M. and Alvaro, N. (2002), “The New Empirics of Economic Growth: Quantile Regression Estimation of Growth Equations', Department of Economics, University of Illinois, Urbana-Champaign, 1206 S. $6^{\text {th }}$ St., 484 Wohlers Hall, Champaign, IL 61820

De Mello, M. Pack, M. and Sinclair, T. (2002). A System of equations model of U.K. tourism demand in neighbouring countries. Applied Economics, 34, 509 - 521

Deaton, A. and Muellbauer, J. (1980a), “An Almost Ideal Demand System”, American Economic Review Vol 70, No. 3 PP 312-326

DeHaan, C. (2007), “The Drivers of Tourism Demand in The U. K”. Tourism and Travel Research Institute.

Divisekera, S. (2003), “A Model of Demand for International Tourism”. Annals of Tourism Research 30(1), 31 49.

Divisekera, S. (2007), "Modelling and Estimation of Tourism Demand Elasticities": A Study of tourist Expenditure Allocation In Australia. CRC for Sustainable Tourism Pty Ltd, Queensland, 2007, pp 6-14 (6)

Divisekera, S. (2009), “Ex-post demand for Australian tourism goods and services”. Tourism Economics, 15(1): $153-180$

Engle, R. F. \& Granger, C. W. J. (1987), “Co-Integration and Error-Correction: Representation, Estimating and Testing',. Econometrica. 55: 257 - 276

Engle, R. F. and Granger, C. W. J. (1987), “Co-integration and Error Correction: Representation, Estimation and Testing". Econmetrica, Vol. 55 No. 2 pp 251-276

Frechtling, D. C. (2001), “Forecasting Tourism Demand: Methods and Strategies”. Oxford, U.K

Frechtling, D. C. (2006), “An Assessment of Visitor Expenditure Methods and Models”. Journal of Travel Research, Volume XX pp 1-10

Fujii, E. T. Khaled, M. and Mak, J. (1985), “An Almost Ideal Demand System for Visitor Expenditures'” Journal of transport economics and policy, Vol. xix No. $2161-171$ pdf

Ghana Statistical Service (2010), “Ghana Population and Housing Census”, Accra, Ghana

Ghana Statistical Service (2018), “Trends in the Tourism Market in Ghana”, Accra, Ghana

Gujarati, D. N \& Porter, D. C. (2009), “Basic Econometric’. The Mcgraw-Hill/Irwin, New York, USA

Lance, R. (2011), “Modelling Tourism Demand in the Caribbean: An Approach Using Spatial Econometrics'” Research and Economic Programming Division

Lelwala, E. I. and Gunaratne, L. H. P. (2008), “Modelling tourism demand using co-integration analysis: a case study for tourist arriving from United Kingdom to Sri Lanka'. A Journal

Li Mei (2005), “Tourism Demand Forecasting by Improved SVR Model. Department of Social Science’, Zhengzhou Tourism College, Henan, P.R. China

Li, G. Song, H. and Witt, S. F. (2004), “Modelling Tourism Demand: A Dynamic Linear AIDS Approach'. Journal of Travel Research, 43, 141-150 
Li, G., Song, H. and Witt, S. F. (2005), “Recent Development in Econometric Modelling and Forecasting”, Journal of Travel Research, 43, 141-150

Li, Y. P. (2005), “ A Study Of China's Domestic Tourist Expenditures Based on an Econometric Model”. Techno Economics and Management Research, 6, 54-55.

Miluwil, J. O. \& Hina, R. (2011), "Measuring of the Macroeconomic Impact of Tourism on Economic Growth". International Journal of Information Technology and Knowledge Management, Volume 4, No. 2 pp699-703

Morey, E. R. (2002), “ Hicksian Demand Functions, Expenditure Functions and Shepard's Lemma”.

Morley, D. (1992), “Television, Audiences and Cultural Studies”, London and New York

Motallebi, M. and Pendel, D. L. (2013), “Estimating an Almost Ideal Demand System Model for Meats in Iran'. Selected Paper Prepared for Presentation at the Agricultural and Applied Economics Associations AAEA \& CAES Joint Annual Meeting, Washington, DC, August 4-6, 2013

Page, S. J. and Connell, J. (2006), “Tourism Modern Synthesis”, London, U. K.

Song, H., Li, G., Witt, S. F. and Alhassansopolos, G. (2011), “Forecasting Tourist Arrivals Using Time-Varying Parameter Structural Time Series Models’'. International Journal.

Song, H., Li, G., Witt, S.F. and Fei, B. (2010), “Tourism Demand Modelling and Forecasting: How Should Demand Be Measured?’’ Tourism Economics 16 (1) pp. 63-81.

Song, H., Romilly, P. \& Liu, X. (2010), “An Empirical Study of Outbound Tourism Demand in the UK”, Pages $611-624$

Song, H., Witt, S. F. And Li, G. (2009), “The Advanced Econometrics of Tourism Demand”, London, United Kingdom

Sotiriadis, M. and Varvaressos, S (2014), “A Strategic Analysis of Greek Tourism: Competitive Position, Issues and Lessons"'..International Journal of Tourism Hospitality and Leisure, Vol 4(2)

Statistics Norway (2013), “An Almost Ideal Demand System Analysis of Non-Durable Consumption Categories', Norway

United Nations (2005), “Household Sample Surveys in Developing and Transition Countries.',

United Nations World Tourism Organization (2015), “'Tourism Highlights”, Madrid, Spain

Zellner, A. (1962), “An Efficient Method of Estimating Seemingly Unrelated Regressions and Test for Aggregation Bias'. Journal of the American Statistical Association, 57: pp. 348-368 